\title{
Protagonismo infantil na educação física: Uma experiência pedagógica com a capoeira
}

\author{
Rodrigo Lema Del Rio Martinsi, Wagner dos Santosii \& \\ André da Silva Melloiii \\ Universidade Federal do Espírito Santo, Brasil \\ Sebastião Josué Votreiv \\ Universidade Estadual do Rio de Janeiro, Brasil
}

\section{Resumo}

Este estudo analisa práticas pedagógicas centradas no protagonismo infantil. O método combina a Pesquisa-Ação Colaborativa com a Metodologia Participativa. Os sujeitos participantes deste estudo são dois bolsistas de iniciação à docência, um professor-supervisor e 25 crianças. Os dados são provenientes de observação participante, registros fotográficos e desenhos, extraídos de uma vivência pedagógica com o conteúdo 'capoeira' nas aulas de Educação Física, em um Centro Municipal de Educação Infantil de Vitória/ES. A análise indica que as crianças, por meio de suas práticas, ressignificam o ensino da cultura mediado pelos adultos e, com base nas produções infantis, o processo de intervenção pedagógica é reorientado, levando em consideração o protagonismo das crianças.

Palavras-chave

Protagonismo; Capoeira; Educação Física; Educação Infantil

\section{Introdução}

A Educação Infantil vem se expandindo no Brasil, especialmente após a Lei de Diretrizes e Bases da Educação Nacional (1996) estabelecer esse 
nível de ensino como primeira etapa da Educação Básica no País. A Emenda Constitucional $n^{\circ}$ 59/2009 tornou obrigatória a matrícula de crianças de quatro e cincos anos de idade na pré-escola em todo território nacional, e o Plano Nacional de Educação (2014-2024) fixou como meta a ser atingida, até 2016, a universalização da pré-escola e a ampliação em $50 \%$ da oferta de vagas em creches para crianças até três anos de idade. Para além desses avanços, as conquistas impactaram a dimensão pedagógica, em relação à concepção de infância, nas instituições dedicadas à educação das crianças pequenas.

As Diretrizes Curriculares Nacionais da Educação Básica (DCNEB) (Brasil, 2013) preconizam que "(...) devem ser abolidos os procedimentos que não reconhecem a atividade criadora e o protagonismo da criança pequena" (p. 93). Em consonância com essa recomendação, algumas instituições e redes de ensino estabelecem práticas pedagógicas que focalizam as crianças como produtoras de cultura e sujeitos ativos dos processos de socialização empreendidos pela escola.

O protagonismo infantil se manifesta em suas culturas de pares ${ }^{1}$, em seus contextos de inserção social, sobretudo o escolar, onde as crianças passam a maior parte da infância. As crianças constroem história e cultura e consomem produtivamente os bens culturais que lhes são ofertados (Certeau, 1994).

Ao valorizar a criança como produtora de cultura e agente de socialização, enfrentamos desafios na dimensão do "como fazer". Portanto, indagamos em que termos podemos considerar as crianças pequenas como protagonistas nos processos de ensino-aprendizagem desenvolvidos pela Educação Física na Educação Infantil. Nessa linha, o Programa Institucional de Bolsas de Iniciação à Docência (PIBID) ${ }^{2}$ do curso de Educação Física da Universidade Federal do Espírito Santo (UFES) desenvolve ações formativas no contexto da Educação Infantil, assumindo as produções das crianças como referência para intervenções pedagógicas desse componente curricular.

Este artigo tem como objetivos descrever como o protagonismo das crianças se manifestou nas aulas de Educação Física e como as intervenções pedagógicas foram conduzidas pelos bolsistas do PIBID em Educação Física (PIBID/EF) da UFES. Para tanto, analisamos uma experiência mediada com o conteúdo 'capoeira', desenvolvida em um Centro Municipal de Educação Infantil (CMEI) de Vitória/ES. 


\section{Percurso teórico-metodológico}

Para analisar a interlocução entre adultos e crianças, combinamos a Pesquisa-Ação Colaborativa (Ibiapina, 2008) e a Metodologia Participativa (Ferreira \& Sarmento, 2008).

As experiências narradas ${ }^{3}$ têm como sujeitos dois bolsistas de iniciação à docência (ID) e um professor-supervisor em trabalho pedagógico com a capoeira, realizado com uma turma de 25 crianças do Grupo $\mathrm{VI}^{4}$ de um CMEl de Vitória/ES. Participamos dos planejamentos e das intervenções e acompanhamos as aulas entre os meses de setembro e dezembro de 2014. Permanecemos 15 semanas no campo e participamos de 30 aulas e de 30 momentos de planejamento.

A Pesquisa-Ação Colaborativa (Ibiapina, 2008) permite indagar a realidade "(...) em que pesquisadores e educadores trabalham conjuntamente na implementação de mudanças e na análise de problemas, compartilhando a responsabilidade na tomada de decisões e na realização das tarefas de investigação" (p. 23). O pesquisador assume postura crítica em relação ao seu próprio objeto de estudo.

Organizamos de forma cíclica as etapas da espiral de ação, reflexão e nova ação, propostas por Ibiapina (2008). Essas etapas se retroalimentam em relação colaborativa entre pesquisadores, bolsistas de ID e professoressupervisores. Dessa forma, compartilhamos as nossas experiências profissionais e de pesquisadores no planejamento das intervenções pedagógicas, na reflexão sobre as ações empreendidas pelas crianças nas atividades propostas e na reconfiguração dessas atividades a serem desenvolvidas em aulas posteriores.

As crianças são protagonistas dos seus processos de socialização, com oportunidade para manifestar suas necessidades e expectativas, segundo pressupostos da Metodologia Participativa ${ }^{5}$ (Ferreira \& Sarmento, 2008). São concebidas como "(...) actores sociais plenos, competentes na formulação e interpretações acerca dos seus mundos de vida" (p. 80). Valorizamos as construções infantis individuais e coletivas, como informantes privilegiados acerca das suas produções culturais. Seguimos Quinteiro (2002) para: "(...) ouvir o que pensam, sentem e dizem as crianças, na perspectiva de que estudar, desvendar e conhecer as culturas infantis constituem-se não 
apenas em mais uma fonte (oral) de pesquisa, mas principalmente em uma possibilidade de investigação acerca da infância" (p. 35).

Analisar o que as crianças fazem e dizem implica assumirmos que "(...) a valorização da voz e acção das crianças é o indicador essencial, sobre o qual se baseia toda a investigação" (Ferreira \& Sarmento, 2008, p. 81). Buscamos captar as produções infantis e, ancoradas nelas, reorientar as práticas pedagógicas desenvolvidas pelos bolsistas de ID e pelo professorsupervisor. As ações táticas ${ }^{6}$ das crianças são calculadas e, por vezes, desafiadoras nas aulas ministradas pelos bolsistas de ID. Interpretamos essas ações como estratégias ${ }^{7}$ nas quais reorientamos as práticas pedagógicas.

Na produção dos dados, utilizamos a observação participante, que foi registrada em diário de campo. Nesse processo, direcionamos uma atenção especial à enunciação ${ }^{8}$, caracterizada pela "fala em ato", ou seja, pela maneira com que as crianças se pronunciavam e se posicionavam na interação com seus pares e com os adultos. Também usamos registros fotográficos para retratar as práticas pedagógicas desenvolvidas, e desenhos para obter informações sobre como as experiências impactavam as crianças.

As imagens fotográficas ${ }^{9}$ são tratadas como representações sociais da realidade. Para Gobbi (2011), as fotografias constroem e reconstroem realidades e, quando circulam em diferentes espaços escolares, "(...) passam a constituir conhecimentos sobre aqueles que os frequentam, sobre as práticas e a construção de diferentes saberes nesses espaços, no que ocultam e evidenciam" (p. 1215). Polissêmicas, permitem inferências de conteúdo e de forma, evidenciando "(...) as culturas infantis que emergem; as culturas docentes que também podem ser percebidas, ou mesmo, questionadas, trazendo aspectos do imaginário e das práticas sociais escolares" (Gobbi, 2011, p. 1215).

Realizamos uma análise da experiência vivenciada ao longo desses quatro meses de inserção no contexto pesquisado. Os dados apresentados focalizam o conjunto processual de como o protagonismo das crianças foi se revelando por meio da linguagem corporal e verbal, permitindo-nos direcionar as práticas pedagógicas com a capoeira a partir dos interesses dos infantis.

O trabalho pedagógico com a capoeira se configurou como um "caso expressivo" (Castanheira, 2004), de modo a permitir uma análise 
pormenorizada de caracterização do grupo social e de suas práticas típicas, capacitando o pesquisador a estabelecer conexões entre eventos e fenômenos.

\section{Apresentação e análise dos dados}

A experiência vivenciada no CMEl "Andorinhas" evidencia o trabalho pedagógico com o conteúdo 'capoeira'. O CMEI "Andorinhas" elegeu o tema Identidade Cultural para desenvolver o projeto pedagógico da Educação Física durante o ano letivo de 2014. Esse projeto foi construído pelo professor-supervisor da escola. Aos bolsistas de ID coube planejar as intervenções pedagógicas. Os temas e conteúdos previstos no projeto visavam a dialogar com os traços culturais que constituem a identidade das crianças, abordando as manifestações da cultura popular e do folclore capixaba. $\mathrm{O}$ trabalho pedagógico em questão contempla elementos da cultura popular, estreitando as relações entre a escola e a cultura local (Zandomínegue \& Mello, 2014)

Analisamos como as crianças reagiram às práticas pedagógicas com a capoeira propostas pelos bolsistas de ID e pelo professor-supervisor. Com base nas reações/ produções infantis, identificamos seus interesses e desejos e, a partir deles, discutimos as intervenções pedagógicas.

Começamos com uma brincadeira proposta pelos bolsistas de ID, que consistia em um 'pique-pega' temático, organizado com elementos da capoeira. Nessa atividade, a criança que estivesse na condição de "pegadora" teria a função de correr atrás das demais, objetivando pegá-las. As que fossem pegas, por sua vez, deveriam permanecer na posição de defesa da capoeira, conhecida como cocorinha. Para que elas voltassem ao jogo, outra criança, que não estivesse na posição de cocorinha, deveria realizar à sua frente algum movimento (golpe) aprendido na aula, livrando-a da condição de "presa".

Registramos, em nosso diário de campo, que as crianças alternavam momentos em que estavam na condição de pegadoras com outros em que preferiam fugir para não serem pegas, sem que isso ocorresse dentro das regras previamente estabelecidas pelos bolsistas. 
As crianças, a cada instante, modificavam a sua condição na brincadeira de acordo com os seus interesses. A partir de suas motivações, entre elas próprias, negociavam em que momentos assumiam a função de pegar e de serem pegos, não partilhando com os adultos esse tipo de decisão. (Diário de campo, 6-102014)

Essa negociação faz parte de um conjunto de "transgressões" das crianças, recorrentes no trabalho com a capoeira. Um desses episódios ocorreu quando algumas crianças do Grupo VI vivenciaram, de modo peculiar, o movimento da "parada de cabeça", conforme mostra a Figura 1:

Figura 1 - Movimento "parada de cabeça"

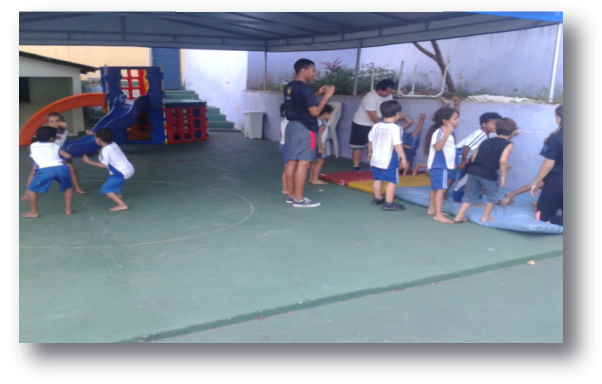

Nessa figura, é possível perceber que, enquanto o professorsupervisor e os bolsistas de ID se preocupam em garantir a realização segura do movimento, três crianças se posicionam no círculo desenhado no chão e começam a simular uma roda de capoeira. Embora nenhum dos adultos presentes tivesse comunicado que aquele círculo seria utilizado com essa finalidade, as crianças empregam elementos aprendidos em aulas anteriores e subvertem a lógica da aula planejada.

As crianças agem taticamente e, à margem do planejamento formal da aula, experimentam alternativas. É nos momentos fugidios do olhar adulto que elas aproveitam para estabelecer relações instituintes de negociação, jogo de papéis e regras acerca das formas de brincar e de operar com os objetos, espaços-tempos e com as atividades que mais lhes interessam (Martins, 2015).

Ao exercerem protagonismo, as crianças resistiram ao controle e à organização espacial da aula. Como afirma Corsaro (2009), "(...) as crianças 
querem criar e compartilhar emocionalmente o poder e o controle que os adultos têm sobre elas" (p. 39). Esse autor cunhou o conceito de reprodução interpretativa para referenciar os aspectos inovadores da participação das crianças em sociedade, especialmente nas suas formas de participação nas culturas de pares, apropriando-se de informações do mundo adulto de forma a atender aos seus interesses próprios enquanto crianças.

Ao percebermos que esse comportamento "transgressor" era recorrente entre as crianças, buscamos identificar, nos planejamentos semanais, os significados dessas ações, expressão dos desejos infantis. Finco (2004) afirma que as crianças "(...) ao encontrarem espaço para a transgressão, vão além dos limites do que é predeterminado" (p. 89), já que elas possuem outros critérios para escolher do que e com quem brincar.

Dessa forma, as ações de "fuga" das crianças foram concebidas em nossos planejamentos como pistas $^{10}$, que permitiram remontar a realidade complexa não experimentável diretamente (Ginzburg, 1989). Mesmo sem falar uma só palavra, a partir da linguagem corporal as crianças conseguem dar visibilidade àquilo que lhes parece fazer mais sentido. Os seus interesses e desejos podem ser observados nas formas astuciosas com que elas se comportaram diante das atividades planejadas pelos adultos. Para Finco e Oliveira (2011),

Apesar de toda bagagem de estereótipos, as crianças pequenas ainda encontram espaços para a transgressão, para a superação e para expressão dos seus desejos. Assim, as crianças pequenas, com seus corpos e com suas espontaneidades, problematizam e questionam esses modelos centrados no adulto. (p. 72)

Com base nessas pistas/transgressões, refletimos com os bolsistas de ID e com o professor-supervisor sobre a necessidade de estarmos atentos aos indícios presentes na espontaneidade das brincadeiras das crianças. Sendo assim, problematizamos com os envolvidos acerca da relevância de se reconfigurar as aulas, no sentido de conferir uma maior liberdade de ação às crianças e permitir que elas expressem corporal e verbalmente os seus desejos.

A Figura 2 mostra uma situação em que os bolsistas de ID e o professor-supervisor colocaram em prática o que havíamos estabelecido, coletivamente: 
Figura 2 - Movimento "Aú"

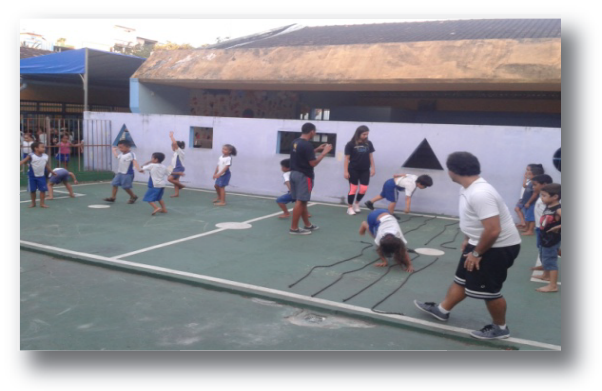

Para essa aula, os bolsistas de ID e o professor-supervisor planejaram uma atividade educativa para realização do movimento conhecido na capoeira como Aú, que consistia em passar pelas quatro cordas expostas no chão, colocando as mãos e os pés nos espaços demarcados por esses objetos.

(...) durante a realização do Aú, embora muitos fizessem conforme as orientações dadas, algumas crianças disseram para o professor: 'Tio, eu já sei fazer'; 'Tio, eu sei dar estrelinha'. Nesse momento, duas crianças pediram à bolsista de ID para realizar o movimento sem o auxílio das cordas. Assim que ela concordou, várias outras crianças acompanharam a dupla e passaram a fazer o Aú fora do espaço determinado. (Diário de campo, 13-10-2014)

A vontade das crianças foi respeitada e a atividade foi efetuada de forma autônoma pelos infantis. Portanto, houve sensibilidade, por parte dos adultos, em não "aprisionar" as crianças em sequência pedagógica que, para algumas, poderia se tornar enfadonha. Para Neira (2008), "(...) o olhar sensível para as produções infantis permitirá conhecer os interesses das crianças, os conhecimentos que estão sendo apropriados por elas" (p. 59).

Segundo Certeau (1985), a análise do caráter ético das práticas ajuda a compreender o cotidiano de quem não se identifica com a ordem estabelecida. Ao contrário, abre um espaço que não é constituído sobre a realidade existente, e sim sobre a vontade de inventar, de criar algo. Para o referido autor, na prática transformadora há sempre uma "vontade histórica de existir".

Parte considerável dessas crianças já devia conhecer o movimento "estrelinha", adquirido a partir de experiências construídas em vivências motoras anteriores, desenvolvidas na rua, na própria escola, em momentos livres ou dirigidos. Portanto, as crianças optaram por realizar o Aú à sua 
maneira, "abrindo espaço" para transformar aquela prática. Logo, fizeram um consumo produtivo dessa atividade ao fabricarem alternativas de uso para esse bem cultural, apropriando-se de elementos do mundo adulto de forma criativa e autoral. As crianças, ao experimentarem os movimentos, não estavam se restringindo a uma reprodução mecânica e/ou passiva destes; antes, nesse ato, elas imprimiram suas marcas, seus sentidos, suas histórias e reconfiguraram a atividade a partir de seus interesses.

De acordo com Benjamin (2002), compreendemos que essa experiência narrada é um atributo tipicamente humano, nomeado de capacidade mimética. A mimese, para o autor, apresenta-se como um ato de reconhecer e produzir semelhanças para compreender e ordenar o mundo, atribuindo-Ihe sentido, de forma que as dimensões da imitação e da criação se interpenetram e as crianças incorporam suas marcas e ressignificações, dando-Ihes autoria própria.

Essas operações infantis nos conduziram, juntamente com os bolsistas de ID e com o professor-supervisor, a realizar reflexões acerca dessas ações táticas empreendidas pelas crianças, a fim de suscitar o debate sobre o protagonismo infantil e, a partir dele, sistematizar as próximas intervenções, de modo a garantir que as práticas pedagógicas atendessem aos anseios e ao potencial criativo das crianças. Esta ação cíclica de observar como as crianças lidam com as atividades propostas, refletir sobre a experiência concreta, para depois planejar as próximas mediações pedagógicas, orienta o processo formativo em curso no PIBID/EF.

Concordamos com Andrade Filho (2013) quando fala da importância de "(...) estudar as experiências de movimento corporal das crianças, objetivando contribuir para que a Educação Física constitua elementos teóricos e metodológicos específicos, capazes de orientar a atuação e a formação do professor" (p. 55). Por esse ângulo, a discussão coletiva acerca das experiências vividas nas aulas permite aos envolvidos repensar as práticas pedagógicas usuais, a fim de reelaborar o planejamento das aulas seguintes, considerando os interesses e desejos das crianças.

Sob essa perspectiva, cabe identificar, nas práticas pedagógicas das aulas de Educação Física, os motivos para a ação das crianças. Esse é um desafio posto aos bolsistas de ID e ao professor-supervisor e requer deles o exercício de um olhar sensível para captar essas nuances e a capacidade de 
conhecê-las a partir delas próprias, considerando as suas experiências como forma de explicitar a sua subjetividade - os modos como entendem, interpretam, negociam e se sentem em relação aos mundos materiais e discursivos que tecem as suas vidas cotidianas (Ferreira \& Sarmento, 2008).

Para Corsino (2007), conhecer as crianças, o que pensam acerca do mundo e seus desejos implica uma sensibilidade de tal ordem que exige um movimento de observação e questionamento, necessário para:

Articular o que as crianças sabem com os objetivos das diferentes áreas do currículo. Implica, também, uma organização pedagógica flexível, aberta ao novo e ao imprevisível; pois não há como ouvir crianças e considerar as suas falas, interesses e produções sem alterar a ordem inicial do trabalho, sem tornálo uma via de mão dupla onde trocas mútuas sejam capazes de promover ampliações, provocar saltos dos conhecimentos. (p. 58)

Nas Figuras 3 e 4, podemos analisar outro exemplo de reorientações das práticas pedagógicas que adotamos nos momentos de planejamento coletivo, fruto desse olhar sensível às indicações emitidas pelas crianças e da escuta atenta ao que elas enunciam. Nesse caso específico, o desinteresse pelas rodas de capoeira no formato habitual, quando elas jogavam entre si ao final de cada aula, serviu-nos de fonte para o debate sobre como melhorar a participação das crianças na atividade proposta. Essa sugestão surgiu após as próprias crianças pedirem que os adultos entrassem na roda e jogassem com elas.

Figuras 3 e 4 - Professor jogando capoeira com as crianças

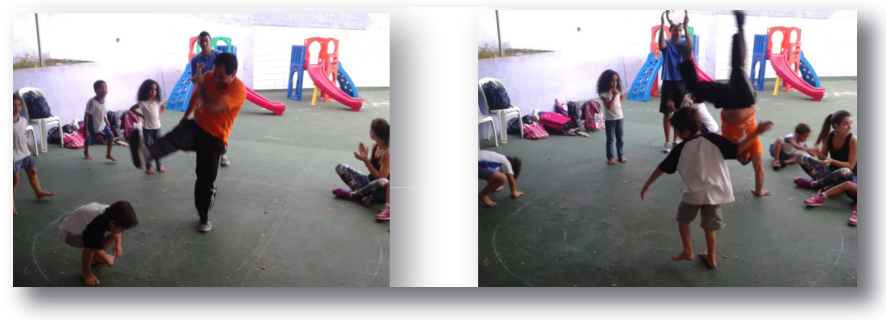

A partir da reivindicação das crianças, tanto os dois bolsistas de ID quanto o professor-supervisor passaram a convidar e ser convidados para jogar na roda, caracterizando, assim, a relação criança/adulto. Tal interação é mencionada nas DCNEBs como ponto de reflexão metodológica e também 
aparece em propostas pedagógicas internacionais, como a de Reggio Emilia, na Itália. A proposta italiana, mesmo sendo uma abordagem centrada na criança, não minimiza o papel do adulto e adota uma lógica de construção dos saberes a partir da interação entre adultos e crianças, entendendo tal interação como um princípio pedagógico para a aprendizagem, para o desenvolvimento emocional autônomo e para a socialização das crianças (Omelczuk, 2009).

Propostas de trabalho pedagógico dessa natureza tendem a considerar essa relação como um dos principais pilares para o desenvolvimento humano integral. Omelczuk (2009) considera que as propostas mais modernas para a infância apostam na qualidade das relações entre os adultos e as crianças e que elas partem "(...) cada vez mais do ponto de vista das crianças para o planejamento pedagógico e para a compreensão da forma mais adequada de lidar com elas, confiando em suas habilidades de expressão, compreensão e problematização da realidade" (p. 16).

A seguir, apresentamos as Figuras 5 e 6, que retratam outro aspecto do trabalho pedagógico com a capoeira que vai além das aulas planejadas pelos adultos. Os registros fotográficos contidos nessas duas figuras foram feitas num momento em que as crianças iam para o pátio brincar livremente ${ }^{11}$ e nos chamaram a atenção pelo modo como começaram a jogar capoeira.

\section{Figuras 5 e 6 - Crianças jogando capoeira fora da aula de Educação}

\section{Física}

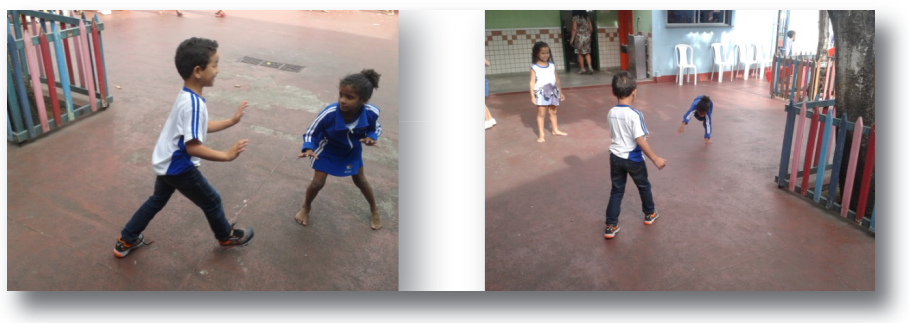

Nesse instante, flagramos as duas primeiras crianças que chegaram ao pátio realizando movimentos aprendidos nas aulas anteriores de Educação Física. O menino fez gestos convidando a menina a jogar capoeira e ela prontamente começa a gingar à sua frente. Mesmo sem a intervenção de um 
adulto e sem a diretividade de uma aula formal, as crianças começam a manifestar suas preferências relacionadas com os conteúdos trabalhados nas aulas de Educação Física, ministradas pelos bolsistas de ID e pelo professorsupervisor do PIBID/EF, exercendo-as no seu tempo de atividade livre. Nessa ação, as crianças ampliam o seu repertório cultural e, por conseguinte, produzem outro sentido para o ato de brincar, pois, como defendem Ferreira e Sarmento (2008), brincar não é, tão somente, uma ação natural e espontânea. Ao contrário, as brincadeiras, especialmente aquelas situadas em instituições escolares, são mediadas pelas experiências vividas.

A vivência exposta nessas figuras se aproxima do conceito de experiência de Larrosa (2004). Para o autor, experiência é tudo aquilo que passamos, o que nos acontece, o que nos toca e deixa marcas. Com efeito, as experiências manifestadas pelas crianças materializam as sensações positivas que elas estão tendo com os elementos da capoeira. A partir do arcabouço simbólico e motor apreendido, as crianças passam a agir no mundo influenciadas pelos bens culturais, mediados pela escola.

As experiências perpassam as relações que os sujeitos estabelecem com o mundo, podendo ser expressas em representações imagéticas. Uma alternativa para se tentar captar como essas experiências têm tocado as crianças é por intermédio dos desenhos. Por essa razão, sugerimos aos bolsistas de ID adotar, como estratégia avaliativa do trabalho pedagógico realizado, a produção de desenhos sobre a capoeira. Nossa decisão toma como base a seguinte defesa de Araújo e Fratari (2011):

Ao desenhar, a criança conta sua história, seus pensamentos, suas fantasias, seus medos, suas alegrias, suas tristezas. No ato de desenhar a criança age e interage com o meio, seu corpo inteiro se envolve na ação, traduzido em marcas que ela mesma produz, se transportando para o desenho, modificandoo e se modificando. (p. 68)

Nas Figuras 7 e 8, apresentamos dois dos desenhos produzidos pelas crianças como parte da avaliação que encerrou o trabalho desenvolvido na Educação Física com a capoeira. Na Figura 7, uma das crianças se autorretratou fazendo o movimento Aú. Também desenhou o professorsupervisor tocando berimbau, com toda essa cena sendo observada por outra coleguinha da turma. Na Figura 8, a criança retratou uma roda de capoeira, tendo a participação dela e de um "primo" que não frequenta o CMEl pesquisado. 
Figura 7 - Desenho representando movimentos da capoeira e o professor tocando berimbau

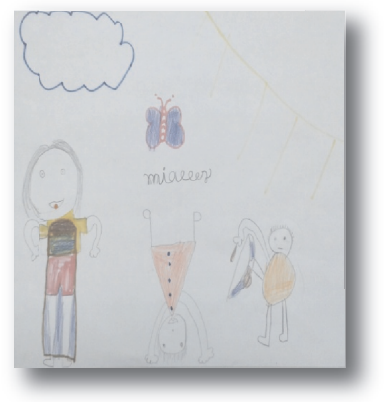

Figura 8 - Desenho representando a roda de capoeira vivenciada nas aulas do PIBID/EF

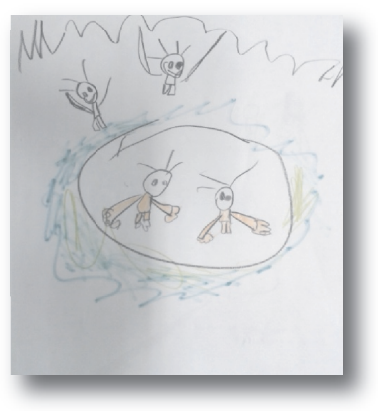

Esses personagens foram nomeados pelas próprias crianças, pois sempre que o desenho era entregue os bolsistas de ID perguntavam sobre o significado das ilustrações. Essa postura evitou tirar conclusões prévias sobre as produções infantis, já que nosso objetivo não era julgar, tampouco interpretar os desenhos.

Registramos, em nosso diário de campo, o contexto em que esses desenhos foram produzidos dentro da sala de aula da turma do Grupo IV:

(...) enquanto as crianças desenhavam, percebemos que um grupinho de crianças, de uma das mesas, começou a entoar um dos cânticos aprendidos por elas durante as aulas de capoeira: 'Xô chuá, cada macaco no seu galho; Xô chuá, eu não me canso de falar; Xô chuá, mas o meu galho é na Bahia...'. Após o início dessa cantoria, outras crianças que estavam sentadas em outras mesas, mesmo permanecendo com as cabeças baixas por estarem 
concentrados na produção dos seus desenhos, também passaram a cantarolar essa música, formando um sonoro coro em toda a sala. (Diário de campo, 1011-2014)

Tomadas por um clima de euforia, as crianças do Grupo VI mantiveram-se cantando enquanto registravam cenas da capoeira vivenciadas nas aulas ministradas pelos bolsistas do PIBID/EF: "Eis que então, num outro grupinho, composto majoritariamente por meninas, surgiu uma nova música, também aprendida nas aulas de capoeira: 'Pula, pula, pula, ô Piaba. A maré tá cheia!'" (Diário de campo, 10-11-2014).

Diante desse cenário, concordamos com Araújo e Fratari (2011) quando defendem que, por meio dos desenhos, a criança é capaz de desenvolver, em maior ou menor grau, os seus sentimentos, pois "(...) quanto maior o envolvimento do sujeito em sua obra, maior a possibilidade de estarem ali presentes as suas alegrias e tristezas, as experiências vivenciadas que lhe provocaram prazer, desprazer, espanto, temor, entusiasmo e muitas outras emoções" (p. 70).

As crianças, ao cantarolar as músicas da capoeira, extrapolaram o que havia sido inicialmente pedido e, além de retratar imageticamente o conteúdo aprendido nas aulas de Educação Física, deram mais uma vez pistas de que existe uma relação de pertencimento, prazer e satisfação com essa prática corporal. Por meio dos desenhos, buscamos fomentar, junto às crianças do Grupo VI, sua autoria e, a partir dela, identificar os sentidos atribuídos às experiências vividas nas aulas mediadas pelos atores do PIBID/EF, bolsistas de ID e professor-supervisor.

Segundo Larrosa (2004), o saber proveniente da experiência vai se constituindo "no sentido" ou no "sem-sentido" do que nos acontece. É adquirido nas formas como respondemos ao que nos acontece durante toda a vida e "(...) no modo como vamos dando sentido ao acontecer do que nos acontece" (p. 27). Assim, percebemos que é por meio da ação de refletir sobre as experiências que potencializamos a aprendizagem e percebemos que as experiências de formação precisam ser interpretadas, pensadas com os sentidos que, por meio delas, são produzidos.

A perspectiva trabalhada pelo programa de escutar as crianças e atentar para as suas indicações, no sentido de materializar nos planejamentos das aulas seguintes os seus interesses e necessidades, auxilia na revisão da 
preocupação do deslocamento do olhar docente comumente centrado no ensino para o da aprendizagem.

(...) o desafio que se coloca para a elaboração curricular e para sua efetivação cotidiana é transcender a prática pedagógica centrada no/a professor/a e trabalhar, sobretudo, a sensibilidade deste/a para uma aproximação real da criança, compreendendo-a do ponto de vista dela, e não no ponto de vista do adulto. (Oliveira, 2013, p. 6)

As relações desencadeadas pelos adultos com as crianças, e entre elas, por meio do conteúdo da capoeira nas aulas de Educação Física, fundam-se na proposta de pôr em evidência o que as crianças estão aprendendo e experimentando. Para Barbosa e Horn (2008), a aprendizagem está intimamente ligada à elaboração de sentido por parte do indivíduo e, portanto, nessa atividade, "(...) os sujeitos adquirem marcos de referência para interpretar as experiências e aprender a negociar os significados de modo congruente com as demandas da cultura" (p. 26).

Inspirados no que preconizam as Diretrizes Curriculares Nacionais da Educação Básica (Brasil, 2013), quando tratam da organização das experiências de aprendizagem no currículo da Educação Infantil, concordamos que cabe aos professores criar oportunidades para que as crianças, no processo de elaborar sentidos pessoais, se apropriem de elementos significativos de suas culturas, não como verdades absolutas, mas como elaborações dinâmicas e provisórias, ressaltando a importância de trabalhar com foco nos saberes oriundos das práticas que as crianças vão construindo, para que se garanta a apropriação e (re)construção, por elas, de novos conhecimentos. Para tanto, é imprescindível observar as ações infantis, individuais e coletivas, no sentido de identificar o significado de sua conduta.

Alicerçados em Finco (2010), afirmamos que as experiências das crianças se constituem pela ação coletiva da cultura infantil e, por essa razão, exigem de nós, pesquisadores da infância, pensarmos em propostas de formação docente calcadas na emergência de novas pedagogias que, de fato, "(...) promovam e recebam com 'bons olhos' a transgressão, a incerteza, a complexidade, a diversidade, a não linearidade, a subjetividade, a singularidade, as perspectivas múltiplas e as especificidades espaciais e temporais" (p. 175). 


\section{Considerações finais}

Entendemos que é possível pensar o trabalho cotidiano dos professores junto às crianças a partir das opções que têm origem nas suas crenças e concepções e que envolvem posturas, atitudes, procedimentos, estratégias e ações. No caso deste estudo, o professor ajudou as crianças a transformar e produzir cultura, assumindo o papel de mediador da aprendizagem. O professor cumpriu um papel de interação e motivação, valorizando a relação com a criança, sem foco na hierarquia entre "quem ensina" e "quem aprende". No desenvolvimento das atividades, os adultos respeitavam as falas das crianças, suas atitudes no decorrer das aulas, participando das atividades com elas.

Oferecemos evidência favorável às possibilidades de se trabalhar os conteúdos da Educação Física, numa perspectiva de respeito às crianças e às suas demandas específicas, para discutir como o protagonismo infantil se revela nas ações táticas empreendidas pelas crianças e como podemos incorporá-las, metodologicamente, no repertório das novas estratégias das aulas de Educação Física na Educação Infantil.

Captamos as manifestações das crianças em episódios vividos nas aulas de capoeira e repensamos a metodologia das aulas, junto com os bolsistas de ID e com o professor-supervisor. A proposição de novas práticas atendeu aos anseios das crianças. Constatamos, assim, que o protagonismo infantil emerge das práticas cotidianas empreendidas pelas crianças. Quando reconhecidas pelo adulto docente, esse conhecimento retorna por meio de ações e atividades que valorizam os desejos e interesses manifestos, corporal e verbalmente, por elas.

Evidenciamos que é por meio de ações "transgressoras" que as crianças expõem, à sua maneira, suas vontades e decisões. E essas ações só se materializam como atividade protagonista, cercada de sentido, se os adultos aceitarem legitimar esse processo. No caso específico deste estudo, esse comportamento infantil se apresentou com frequência no contexto das aulas e, por essa razão, optamos por discutir com os bolsistas de ID e o professor-supervisor os significados dessa ação das crianças.

Neste trabalho, correlacionamos os conceitos de consumo produtivo e de reprodução interpretativa realizados pelas crianças diante das atividades 
de capoeira propostas pelos adultos. Contudo, merece nova investigação a vinculação dialógica entre o conceito de Certeau e o de Corsaro, para melhor compreendermos como as crianças lidam com os bens culturais a elas ofertados e como elas ressignificam as atividades propostas pelos adultos. A experiência aqui relatada, da capoeira, contribuiu para a construção de nova concepção de infância na formação dos adultos envolvidos no programa.

\section{Notas}

1 Corsaro (2009) define cultura de pares como sendo "(...) um conjunto estável de atividades ou rotinas, artefatos, valores e interesses que as crianças produzem e compartilham na interação com seus pares" (p. 32).

2 O PIBID é um programa do governo federal, que visa elevar a qualidade da formação docente em todo País, distribuindo bolsas para estudantes da licenciatura, professores-supervisores das escolas públicas conveniadas e para docentes das universidades para coordenar os subprojetos de cada área do conhecimento.

3 Aprovadas pelo Comitê de Ética em Pesquisa da UFES, sob o Parecer $n^{\circ}$ 865.827/2014.

4 São crianças com faixa etária entre cinco e seis anos.

5 A Sociologia da Infância, ao assumir que as crianças são atores sociais plenos, capazes de revelar e interpretar os seus mundos de vida, passa a utilizar esse tipo de metodologia como recurso investigativo, no sentido de atribuir aos infantis o estatuto de sujeitos do conhecimento (Ferreira \& Sarmento, 2008).

6 Para Certeau (1994), as ações táticas são calculadas e determinadas pela ausência de um lugar próprio. São formas astuciosas de subverter a ordem imposta.

7 A estratégia é a ação institucionalizada que emerge nas relações assimétricas de poder, impostas pelo detentor da autoridade constituída e exercida num lugar próprio (Certeau, 1994).

8 Para Certeau (1994), a enunciação é de grande utilidade para a descrição das "maneiras de fazer" cotidianas e das apropriações que os sujeitos fazem da cultura do mundo ordinário.

9 Todas as imagens de crianças apresentadas neste estudo tiveram autorização prévia de seus responsáveis, concedida por meio de formulário próprio da escola onde a pesquisa foi desenvolvida.

10 Para Ginzburg (1989), o cotidiano oferece pistas que auxiliam na compreensão dos fenômenos da realidade. Ele denomina essa percepção de método indiciário.

11 Todas as turmas desse CMEI têm 40 minutos reservados ao chamado "horário de pátio", que se configura como um tempo da rotina destinado para as crianças brincarem sem a diretividade de um adulto. 


\section{Referências}

Andrade Filho, N. F. (2013). Observação compreensivo-crítica das experiências de movimento corporal das crianças na educação infantil. Revista Movimento, 19(1), 55-71.

Araújo, R. M., \& Fratari, M. H. D. (2011). O olhar do educador infantil frente ao desenho infantil e suas contribuições. Revista da Católica, 3(5), 66-75.

Barbosa, M. C., \& Horn, M. G. S. (2008). Projetos pedagógicos na educação infantil. Porto Alegre: Grupo A.

Benjamin, W. (2002). Reflexões sobre a criança, o brinquedo, a educação. São Paulo: Duas Cidades.

Brasil (2013). Diretrizes curriculares nacionais para a educação básica. Brasília: MEC/SEB.

Castanheira, M. L. (2004). Aprendizagem contextualizada: Discurso e inclusão na sala de aula. Belo Horizonte: Autêntica.

Certeau, M. (1985). Teoria e método no estudo das práticas cotidianas. In Anais do Encontro Cotidiano, Cultura Popular e Planejamento Urbano. São Paulo: Faculdade de Arquitetura e Urbanismo da Universidade Estadual de São Paulo.

Certeau, M. (1994). A invenção do cotidiano - Artes de fazer ( $8^{a}$ ed.). Petrópolis: Vozes.

Corsaro, W. (2009). Reprodução interpretativa e cultura de pares. In F. Muller \& A. M. A. Carvalho (Orgs.), Teoria e prática na pesquisa com crianças: Diálogos com William Corsaro (pp. 31-50). São Paulo: Cortez.

Corsino, P. (2007). As crianças de seis anos e as áreas do conhecimento. In J. Beauchamp, S. D. Pagel, \& A. R. Nascimento (Orgs.), Ensino fundamental de nove anos: Orientações para a inclusão da criança de seis anos de idade (pp. 57-68). Brasília: Ministério da Educação.

Ferreira, M., \& Sarmento, M. J. (2008). Subjectividade e bem-estar das crianças: (In)visibilidade e voz. Revista Eletrônica de Educação da UFSCar, 2(2), 60-91.

Finco, D. (2004). Faca sem ponta, galinha sem pé, homem com homem e mulher com mulher: Relações de gênero nas brincadeiras de meninos e meninas na préescola (Dissertação de Mestrado). Faculdade de Educação da Universidade Estadual de Campinas, Campinas/SP.

Finco, D. (2010). Educação infantil, espaços de confronto e convívio com as diferenças: Análise das interações entre professoras e meninas e meninos que transgridem as fronteiras do gênero (Tese de Doutorado). Faculdade de Educação da Universidade de São Paulo, São Paulo/SP.

Finco, D., \& Oliveira, F. (2011). A sociologia da pequena infância e a diversidade de gênero e de raça nas instituições de educação infantil. In A. L. G. Faria \& D. Finco (Orgs.), Sociologia da infância no Brasil (pp. 55-80). Campinas: Autores Associados.

Ginzburg, C. (1989). Mitos, emblemas, sinais: Morfologia e história. São Paulo: Cia. das Letras.

Gobbi, M. (2011). Usos sociais das fotografias em espaços escolares destinados à primeira infância. Revista Educação \& Sociedade, 32(117), 1213-32. 
Ibiapina, I. M. L. M. (2008). Pesquisa colaborativa: Investigação, formação e produção de conhecimentos. Brasília: Líber Livro Editora.

Larrosa, J. (2004). Linguagem e educação depois de Babel. Belo Horizonte: Autêntica.

Martins, R. L. R. (2015). O Pibid e a formação docente em educação física para a educação infantil (Dissertação de Mestrado). Centro de Educação Física e Desportos da Universidade Federal do Espírito Santo, Vitória/ES.

Neira, M. G. (2008). A educação física na educação infantil: Algumas considerações para a elaboração de um currículo coerente com a escola democrática. In N. F. Andrade Filho \& O. Schineider (Orgs.), Educação física para a educação infantil: Conhecimento e especificidade (pp. 45-96). São Cristóvão: UFS.

Oliveira, Z. M. R. (2013). Novas diretrizes para a educação infantil. Salto para o futuro, 9, 4-9.

Omelczuk, F. (2009). Conversando com crianças na educação infantil: Suas percepções sobre as situações e interações vividas no espaço escolar (Dissertação de Mestrado). Faculdade de Educação da Universidade Federal do Rio de Janeiro, Rio de Janeiro.

Quinteiro, J. (2002). Infância e educação no Brasil: Um campo de estudos em construção. In A. L. Faria, Z. B. F. Demartini, \& P. D. Prado (Orgs.), Por uma cultura da infância: Metodologia de pesquisa com crianças (pp. 19-47). Campinas: Autores Associados.

Zandomínegue, B. A. C., \& Mello, A. S. (2014). A cultura popular nas aulas de educação física. Curitiba: Appris.

\section{Legislação}

Emenda Constitucional $n^{\circ}$ 59, de 11 de novembro de 2009. Brasília, DF. Prevê a obrigatoriedade do ensino de quatro a dezessete anos.

Lei n. ${ }^{\circ}$ 13.005, de 25 de junho de 2014. Brasília, DF. Aprova o Plano Nacional de Educação para o decênio 2014-2024.

Lei $n{ }^{\circ}$ 9.394, de 20 de dezembro de 1996. Brasília, DF. Dispõe sobre as diretrizes e bases da educação nacional. 


\section{PAPEL DE LOS NIÑOS EN LA EDUCACIÓN FÍSICA: UNA EXPERIENCIA EDUCATIVA CON LA 'CAPOEIRA'}

\section{Resumen}

Este estudio analiza las prácticas de enseñanza centradas en el protagonismo de los niños. El método combina la Investigación-Acción Colaborativa con la Metodología Participativa. Los participantes de este estudio son dos becarios de iniciación a la enseñanza, un profesor-supervisor y 25 niños. Los datos provienen de la observación participante, registros fotográficos y dibujos, elaborados a partir de una experiencia pedagógica con la capoeira en las clases de Educación Física, en un Centro Municipal de Educación Infantil de Vitória/ES. El análisis indica que los niños, a través de sus prácticas, resignifican la enseñanza de la cultura mediada por los adultos $y$, basado en las producciones de estos niños, el proceso de intervención educativa se reorienta, teniendo en cuenta el papel de los niños.

Palabras-clave

Protagonismo; Capoeira; Educación Física; Educación Infantil

\section{CHILDREN'S PARTICIPATION IN PHYSICAL EDUCATION: AN EDUCATIONAL EXPERIENCE WITH 'CAPOEIRA'}

\section{Abstract}

This study analyzes teaching practices focused on children's participation. The method used in the study combines Collaborative Action-Research with Participatory Methodology. Participants of this study are two teaching fellows, a teacher-supervisor and 25 children. The data were derived from participant observation, photographic records and drawings, collected from a pedagogical experience with the content "capoeira" in Physical Education classes in a municipal institution for childhood education in Vitória/ES. The analysis indicates that children, within their practices, resignify the teaching of culture 
mediated by adults and, based on children's productions, the educational intervention process is reoriented, considering the participation of children.

Keywords

Children participation; 'Capoeira'; Physical Education; Childhood education

Recebido em julho/2015 Aceite para publicação em abril/2016

i PROTEORIA (Instituto de Pesquisa em Educação e Educação Física), Universidade Federal do Espírito Santo, Brasil.

ii PROTEORIA, Universidade Federal do Espírito Santo, Brasil.

iii PROTEORIA, Universidade Federal do Espírito Santo, Brasil.

iv PROTEORIA, Universidade Estadual do Rio de Janeiro, Brasil.

Toda a correspondência relativa a este artigo deve ser enviada para: Rodrigo Lema Del Rio Martins, Rua Maria de Oliveira Maresguia, $n^{\circ}$ 101, Apto 1704 (torre Roma), Praia de Itaparica, Vila Velha-ES, Cep: 29.102-245, Brasil. E-mail: rodrigoefrural@hotmail.com 